\title{
Standard Regulation of Occupational Health Requirements of Heat Environments at SMEs
}

\author{
Listiani Nurul Huda \\ Industrial Engineering Department \\ Faculty of Engineering, Universitas Sumatera Utara \\ Jl. AlmamaterKampus USU Medan 20155, Indonesia \\ E-mail: Inurulh@gmail.com
}

\begin{abstract}
Health work environment is one of the determining factors in the improvement of the quality and productivity of work in an enterprise. Health observation work on most small to medium enterprises (SMEs) are often overlooked. But on the other hand is around $80 \%$ of Indonesia's economy is sustained by SMES. In this study, the observation is done at one of the SME food processed ubi. The problem was found on the floor of the production was the workers suffered exposure to heat from the working space temperature of $27 \mathrm{oC}$ until $290 \mathrm{C}$ with doing the job that categorized the weight along the 8 -hours of work. The temperature has exceeded the threshold Value (NAB) set by the Indonesia national standard (SNI) 16-7063-2004 and Regulation of the Minister of Health No. 70 Year 2016. This heat exposure affects the performance of the work and the long-term effects of stimulate i.e. the occurrence of enlarged blood vessels may result in fatal condition/stroke. The purpose of this research is to create a work environment that is healthy and comfortable through the thermal condition improvement in production floor. Thermal analysis is done by calculating the heat stress index (HSI), the value of the Wet Bulb Globe Temperature (WBGT), and the old maximum heat exposure recommendations allowed (duration limited exposure). The results showed the average value of HSI $\mathbf{9 5 . 1 3 \%}$ indicating that exposure is on the level of heat pressure is very heavy. Standard assessment above uses standard NIOSHbased climate data America. These findings indicate that the indicators used in the SNI 16-7063-2004 and Regulation of the Minister of Health No. 70 Year 2016 is a necessary adjustment to applied work set up the climate in Indonesia.
\end{abstract}

Keywords-SNI, HSI, WBGT, DLE, SME

\section{INTRODUCTION}

Health work environment is one of the determining factors in the improvement of the quality and productivity of work in an enterprise. Health observation work on most small to medium enterprises (SMEs) are often overlooked. But on the other hand is around $80 \%$ of Indonesia's economy is sustained by SMES. Health work environment affected by thermal comfort on the physical work environment. Thermal comfort (thermal comfort) is a condition where the mind expressing the satisfaction of thermal environmental conditions [1]. One of the ways to make the environment a comfortable working place is by minimizing heat stress. The longer the exposure to heat so fewer levels of productivity operators in doing the work[2]. Heat Stress in the work environment negatively impact the productivity of operators affected by exposure to heat [3].

Heat exposure against the workers on the floor caused by the production process the production of which is still carried out manually by workers. This condition requires that workers dealing directly with temperature up to $200{ }^{\circ} \mathrm{C} 190{ }^{\circ} \mathrm{C}$ for 9 hours of work so that the body of workers exposed to direct heat. The temperature of the climate work around the floor production ranged from 27.43 up $28.39{ }^{\circ} \mathrm{C}$ with a heavy work load category. The temperature has exceeded the working climate for $\mathrm{NAB}$ the workload weighing $25{ }^{\circ} \mathrm{C}$ set by Indonesia national standard (SNI) 16-7063-2004. In addition to air temperature, hot climate that occurs in the workplace are caused by a combination of wind speed and humidity. Based on the foregoing, the initial measurement against wind speed obtained of $0.29 \mathrm{~m} / \mathrm{s}$ and the average humidity in the get of $68.4 \%$.

The presence of heat exposure and the environmental conditions of work that are less supportive of work performance resulted in workers at the production floor be not optimal. To reduce the effects of heat are felt to the workers, the workers washed their faces with water repeatedly performed ranges from 15-20 seconds. The condition occurs each day and the activity is an activity that is not productive for the company. Based on the above description, the problems faced by SMES is the exposure of workers of profaning the body heat during 19 hours of work at the production floor. These conditions resulted in the performance work that is not marked with the optimal percentage of non productive work time. The purpose of this research is to create a work environment that is healthy and comfortable through the thermal condition improvement in production floor.

\section{METHOD AND EQUIPMENT}

In this study, the observation is done at one of sweet potato chips processed SMES in Medan. The subject was observed overall operator in production floor working around the area of the pan. This is due to close here's workers are exposed to the heat from the pan. The population of this research is the overall operators at work stations which amounted to 16 people. The taking of the sample data used are drawn using a 
sampling technique of total number of samples taken, equal to the number of population.

Research begins with early observations and interviews do directly against the operator in the production floor. Then Hawk data retrieval is done directly by using the measuring tools. Data taken in the measurement data of air temperature, the temperature of the dry, wet temperature, temperature, humidity, wind speed and pulse. The instruments used in this study i.e., 4 in 1 environmental that serves to measure temperature, humidity, light intensity and noise, Globe Thermometer to measure the temperature of the wet, dry and temperature is the temperature of the ball, Anemometer that serves to measure wind speed, a functioning Tensoval to measure blood pressure and pulse rate, thermal questionnaire used to get information about privacy workers and clothing insulation workers. This questionnaire consists of two parts, the first part, namely the type of clothing worn and the second part is about the sensation of thermal conditions where Likert scale using the answer that has a scale of +2 to -2 as shown in Table 1..

Table 1 semantic Questionnaire Vote

\begin{tabular}{|c|c|}
\hline Likert Scale & Thermal Sensation Vote \\
\hline+2 & Hot \\
\hline+1 & Warm \\
\hline 0 & Neutral \\
\hline-1 & Slighlt Cool \\
\hline-2 & Cold \\
\hline
\end{tabular}

Determination of the measurement point on the research following the ASHRAE Standard 55 (2004), ACGIH (2007) and Havenith (2005) and Stanton (2005; 60-7), a measurement point should follow the following conditions:

1. Measurement point is at the operator's work area for quite a while exposed to heat.

2. The operators feel the heat exposure likely to cause discomfort and tends to cause the effect of stress when activity on those points.

3. The number of measurement points, there are no definite numbers (minimum, maximum or range), so the number of measurement point will be based on the conditions of the workplace

4. Conditions of measurement in General is based on a grid location in the work area. The grid is valid up to $5 \mathrm{~m}$ intervals around the point of measurement.

The second is a measurement standard at a height of 0.1 ; 1.1 and 1,7 from the floor. $0.1 \mathrm{~m}$ height from the floor is assumed as the height of the operator's ankles while a height of 1.1 and 1.7 meters in succession as it is assumed as the height of the sit and stand operator. The value is used as the basis for the calculation of the Heat stress Index (HSI) as well as the value of the Duration Limit of Exposure (DLE) which is obtained the formula from bookNaville Stanton [4].

\section{RESULT AND DISCUSSION}

Thermal sensation and comfort level of the perceived impact assessment questionnaire is obtained from the thermal conditions used to obtain personal information on the psychology of thermal comfort. The answers to the questionnaire are given in the form of a scale of -2 to +2 each question in the questionnaire given categories respectively. Graph data of thermal sensation and comfort perception of workers can be seen in Figure 1.

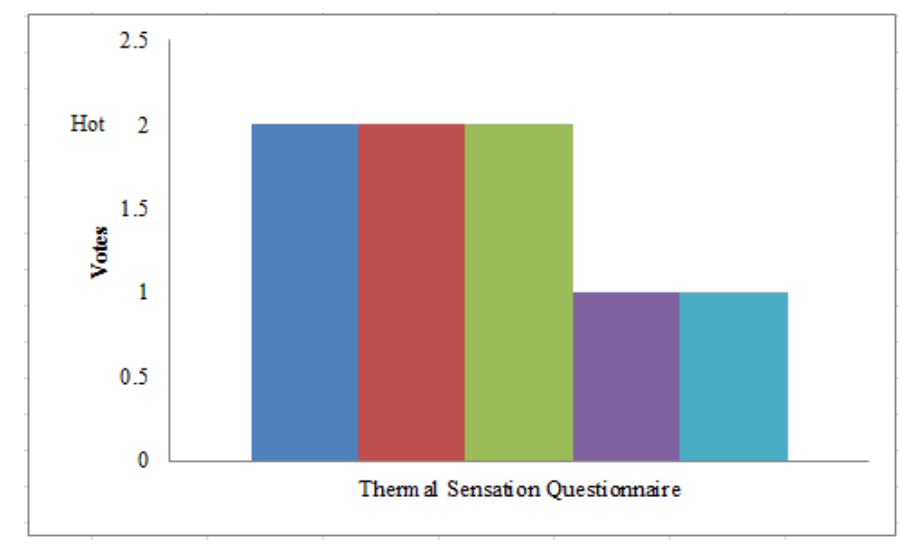

Figure 1Thermal Sensation Votes for 5-Operators

From the above data is obtained that the average worker to feel the sensation of thermal ranges hot. This indicates that the existing working environment gives a atmosphere of work hot and uncomfortable. This is likely to result in the workers feel tired due to the effects of heat goes into the body that tend to disturb the thermal regulation of the body. The effect is clearly visible is the excessive transpiration of the workers due to the heat caused by the working environment around. The temperature around the workers in accordance with the points of measurement at a height other than that workers are feeling the effects of the heat that caused disruptive work and expect a colder working environment. This is apparent from the thermal conditions in a room that is shown in Figure2.

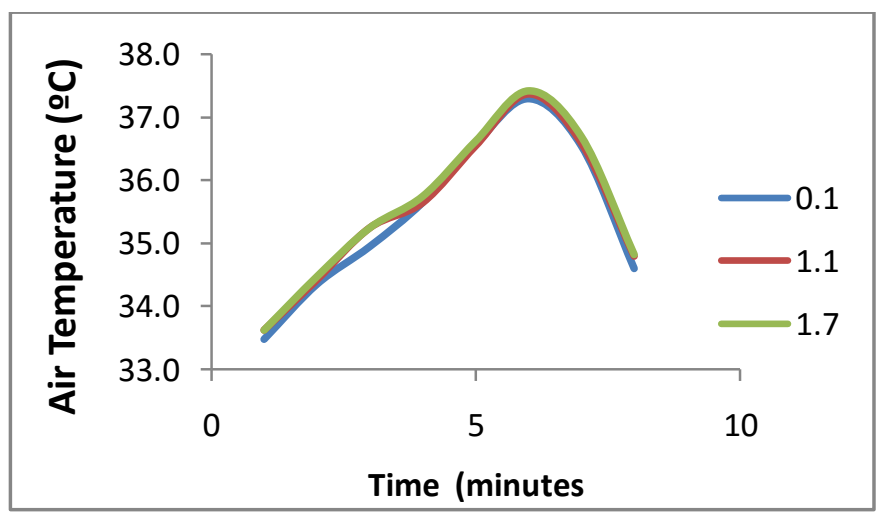

Figure 2 Air Temperature with Respect to Time and Altitude 
Figure 2 explains that there was no significant difference in temperature for each altitude. This indicates that the condition of the indoor air is uniform. This means that the operator will feel the same heat at the time of the working position of the squat, bending or standing. At any position of the operator will feel the same sensation.

Based on Figure 2 then retrieved the value of the temperature that is affected by the condition of dry and wet air called temperature Wet Bulb Globe Temperature (WBGT) as shown in Figure 3.

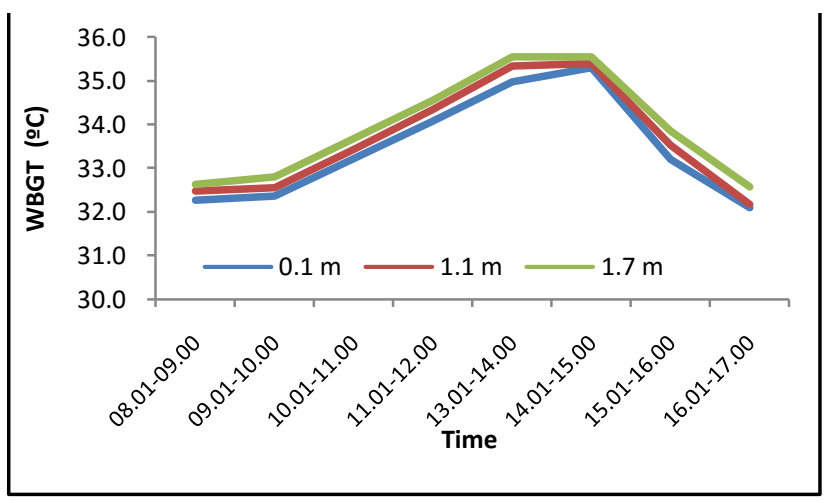

Figure 3WBGT Values at Different Altitude

Figure 3 shows that the WBGT values overall are above 30 ${ }^{\circ} \mathrm{C}$ for all the working height of the gradient starting from the early work of until the end of the work is done. This indicates that the heat in a frying pan the workspace experience heat exposure that tend to cause heat due to work stress. According to the rules set by the SNI Number 16-7063-2004 stated that the threshold value of the working climate at hot environment by WBGT calculation determine as followed :

a)For a light workload, allowable WBGT is $30.0^{\circ} \mathrm{C}$

b) For moderate workload, allowable WBGT is $26.7^{\circ} \mathrm{C}$

c) For heavy workload, allowable WBGT is $25,0^{\circ} \mathrm{C}$

As for the work carried out at the furnace, the operator workload categorized as a heavy workload, so based on the SNI regulation the allowable limit of WBGT of teh workstation is $30.0^{\circ} \mathrm{C}$. While in actual conditions the value of WBGT is above $30{ }^{\circ} \mathrm{C}$. This indicates that conditions in the workstation was exceed the suggested kimit by SNI.So is the case with Regulation of the Minister of Health No. 70, 2016 are shown in Table 2 at the below.

Table2. Regulation of the Minister of Health No. 70 Year 2016

\begin{tabular}{ccccc}
\hline $\begin{array}{c}\text { Allocation } \\
\text { working } \\
\text { time and } \\
\text { rest time }\end{array}$ & Light & Medium & Heavy & $\begin{array}{c}\text { Very } \\
\text { Heavy }\end{array}$ \\
\cline { 2 - 5 } $75 \%-100 \%$ & 31.0 & 28.0 & $*$ & $*$ \\
$50 \%-75 \%$ & 31.0 & 29.0 & 27.5 & $*$ \\
$25 \%-50 \%$ & 32.0 & 30.0 & 29.0 & 28.0 \\
$0 \%-25 \%$ & 32.5 & 31.5 & 30.0 & 30.0 \\
\hline
\end{tabular}

Based on the above Regulation of the Minister of Health with the actual conditions in the frying pan showed that for the work belongs to the WBGT values at the heavy frying pan requires allocation of work ranges from 0 to $25 \%$. This means that operators are not allowed to work or if the work is only permitted in the amount of $25 \%$ of the working time set by the company. The rest of the time was used to rest. If it is running then there wouldn't be companies that can employ the operator and do the production process because the conditions of the working environment are exposed to heat. But in reality none of the company impose the provisions of Regulation of the Minister of Health. This indicates that either the SNI or the Regulation of the Minister of Health is not eligible to apply for the climate in the city of Medan in particular andIndonesia area in general. On the other part, more than thousands of SMEs producing chips or snack that available in Indonesia. Both of these regulations, the SNI Number 16-7063-2004 andRegulation of the Minister of Health No. 70 Year 2016 need an adjustment to be applied in accordance with the climate and weather in Indonesia.

WBGT values obtained from Figure 3 is used to obtain the value of stress due to exposure to heat which is felt during the frying process operator work time. The operators of a frying pan tend to experience the effects of stress in the work. This is shown by the value of the HSI at the height of 1.7 metres which assumed the position of operators that generally occurs when working, see Table 3.

Table 3. The value of the HSI at the Height of 1.7 meter Above Floor

\begin{tabular}{cccccccc}
\hline Point & $\begin{array}{c}\text { Gradient } \\
\text { Height } \\
(\mathbf{m})\end{array}$ & $\mathbf{t}_{\mathbf{r}}$ & $\mathbf{c}$ & $\mathbf{R}$ & Ereq & Emax & $\begin{array}{l}\text { HSI } \\
(\%)\end{array}$ \\
\hline 1 & $\mathbf{1 . 7}$ & 32.78 & -1.78 & 9.75 & 172.03 & 176.71 & 97.35 \\
2 & $\mathbf{1 . 7}$ & 32.17 & -1.34 & 12.43 & 168.90 & 176.85 & 95.50 \\
3 & $\mathbf{1 . 7}$ & 32.24 & -1.13 & 12.12 & 169.00 & 180.38 & 93.69 \\
4 & $\mathbf{1 . 7}$ & 31.66 & -1.11 & 14.68 & 166.4 & 176.85 & 94.10 \\
\hline \multicolumn{7}{c}{ Average } \\
\end{tabular}

Table 3 showed that the average value of Heat Stress Index (HSI) at the height of 1,7 meters above the floor was $95.13 \%$. According to the NIOSH indicators as shown in Table 4 that the HSI value was indicated that the effect of 8-hours exposure of heat on operators are having a very severe heat strain. In that condition, the impact to the work is the operators selected by medical examination adequate water and salt intake. This means the perceived heatconditions would be able to interfere with operators'health and comfort. 
Table4 Heat Stress Index NIOSH

\begin{tabular}{|c|c|c|}
\hline HSI & $\begin{array}{l}\text { Effect of } 8-h \\
\text { Exposure }\end{array}$ & Work Impact \\
\hline-20 & Mild cold strain & Recovery from heat exposure \\
\hline 0 & No thermal strain & None \\
\hline $10-30$ & $\begin{array}{l}\text { Mild to moderate } \\
\text { heat strain }\end{array}$ & $\begin{array}{l}\text { Little impact on physical } \\
\text { work; possible impairment of } \\
\text { skilled work }\end{array}$ \\
\hline $40-60$ & Sever & $\begin{array}{l}\text { Health threat for unit } \\
\text { workers; } \\
\text { necessary }\end{array}$ \\
\hline $70-90$ & $\begin{array}{l}\text { Very severe heat } \\
\text { strain }\end{array}$ & $\begin{array}{l}\text { Workers selected by medical } \\
\text { examination adequate water } \\
\text { and salt intake necessary }\end{array}$ \\
\hline 100 & $\begin{array}{l}\text { Maximum daily } \\
\text { thermal strain }\end{array}$ & $\begin{array}{l}\text { Tolerate only by fit, } \\
\text { acclimatized young workers }\end{array}$ \\
\hline$>100$ & $\begin{array}{l}\text { Limited exposure } \\
\text { time tolerable }\end{array}$ & Body core temperature rises \\
\hline
\end{tabular}

While the results of the calculations of Duration Limited Exposure (DLE) obtained that an average value for DLE a minimum of 30 minutes while the average value of a maximum of 36 minutes DLE. In the practical field, it is difficult to be accepted by any company that is in Indonesia to be applied in the exercise of its activity. Several studies conducted in Indonesia also obtained the same results as studies conducted by M. A. Nuruzzaman, et al regarding the influence of the different level of air humidity on low temperature indoors against thermal comfort [5], Erna Winansih, et al regarding thermal comfort at the street corridor around public places[6], SarindaArlik, et al on the analysis of the change of thermal comfort against the room temperature[7].

Therefore, the application of the standards and regulations of the Government of Indonesia who adopt the values of the condition in the country that weather is not climate and corresponding to the city of Medan in Indonesia in particular and in General to consider or adjusted.

\section{CONCLUSSION}

Data collection, analysis and discussion has been done then the conclusion that the average value of HSI $95.13 \%$ indicating that exposure is on the level of heat pressure is very heavy. The use of a turbine ventilator can reduce the value of the HSI and the duration of exposure to the heat has increased in accordance with the standards of the assessment of the NIOSH-based climate data America. Therefore the Government should establish a policy already on standard and environmental health requirements of industrial work that really suit the climate in Medan Indonesia in particular and General. These findings indicate that the indicators used in the SNI 16-7063-2004 and Regulation of the Minister of Health No. 70 Year 2016 is a necessary adjustment to applied work set up the climate in Indonesia.

\section{REFERENCES}

[1] Parsons, K.C. 2003. "Human Thermal Environment.London andNew York": Taylor \& Francis Group

[2] Suarbawa, "Suhu Lingkungan Kerja Perapen yang Panas dapat Meningkatkan Beban Kerja dan Menurunkan Produktivitas Perajin Gamelan Bali”, ISSN: 978-602-8817-72-1, Proceeding Seminar Nasional dan Kongres PEI 2015, pp.9-13.

[3] Venugopal,VidyaVidhya.2015.Occupational Heat Stress Profiles in Selected Workplaces in India.India:International Journal of Environment Research and Public Health.

[4] Naville, Stanton dkk. 2005. Handbook of Human Factors and Ergonomics Method. London: CRC Press.

[5] Nuruzzaman, M. A., et al, "Pengaruh Tingkat Kelembaban Udara yang Berbeda pada Suhu di dalam Ruangan Terhadap Kenyamanan Termal", Proceeding SENTI UGM, ISSN: 978-602-73431-0-8, 2015, pp.30-34

[6] Winansih, Erna, "Thermal Comfort at The Street Corridor Around Public Places", Journal of Islamic Architecture Vol. 3 issue. 4, 2015, ISSN 2086-2636, pp. 177-182.

[7] Sarinda A., dkk, " Analisis Perubahan Suhu Ruangan Terhadap Kenyamanan Termal", Journal Pembelajaran Fisika, Vol. 6 No. 3, pp.312-318.

[8] Altwood, DennisA,et.al.,2004,ErgonomicSolutions fortheProcess Industries(UnitedStates: ElSevier)

[9] Auliciems,AndrisandStevenV.Szokolay.ThermalComfort(Brisband)

[10] Gallo,C.,dkk.ArchitectureComfortandEnergy(Amsterdam:Elsevier) 